ЯЗЫК ПРАВА

УДК 34.01, ББК 67. Х., ГРНТИ 10.07.61, КОД ВАК 12.00 .01

\title{
Даркнет как ускользающая сфера правового регулирования
}

\author{
А. А. Васильев ${ }^{1}$, Ж. И. Ибрагимов ${ }^{2}$, О.В. Васильева ${ }^{1}$ \\ ${ }^{1}$ Алтайский государственный университет \\ 656049, г.Барнаул, проспект Социалистический, д.68, E-mail: anton_vasiliev@mail.ru \\ ${ }^{2}$ Евразийский национальный университет им. Л.Н. Гумилева \\ Республика Казахстан, 010008 г. Астана, Алма-атинский район, \\ ул. Қаныша Camпаева, E-mail:zhamaladen@mail.ru
}

\begin{abstract}
Правовая система России в последние десятилетия очевидно столкнулась с вызовами глобальной электронной сети. Связаны они прежде всего с тем, что многие группы правоотношений, традиционно существовавшие в «материальном» виде, перемещаются в киберпространство. Речь идет не только о масштабной цифровизации сферы купли-продажи, но и о тех областях права, в отношении которых их перемещение в интернет ранее никто не предполагал (сфера государственных услуг, электронное избирательное право и пр.). Еще более угрожающей представляется проблема использования Даркнет в криминальных сферах.

Отсутствие какого бы то ни было системного правового регулирования в этой области и даже минимального набора основных правовых терминов делает отечественное законодательство беззащитным перед стремительно развивающимся Даркнентом. В статье предлагается авторское осмысление основных проблемных вопросов Даркнета как предмета правового регулирования, соотношение идей свободы и анонимности в сети и защиты государственных и частных интересов. Формулирование концепции правового регулирования в отношении Даркнета должно послужить отправной точкой на этом пути.
\end{abstract}

Ключевые слова: цифровое право; интернет-право; Даркнет; криптовалюта; кибербезопасность; анонимность; свобода

\section{Darknet as an escaping sphere of legal regulation}

\author{
A.A. Vasiliev ${ }^{1}$, Zh.I. Ibragimov ${ }^{2}$, O.V. Vasileva $^{1}$ \\ ${ }^{1}$ Altai State University \\ 656049, Barnaul, Sotsialisticheskiy Prospekt,68,E-mail:anton_vasiliev@mail.ru \\ ${ }^{2}$ L.N. Gumilyov Eurasian National University \\ Republic of Kazakhstan, 010008 Astana, Alma-Ata district, Kanysh Satpayev St. \\ E-mail: zhamaladen@mail.ru
}

\begin{abstract}
The legal system of Russia in recent decades has obviously faced the challenges of the global electronic network. They are connected primarily with the fact that many groups of legal relations, which traditionally existed in the "material" form, ar e moving into cyberspace. It does not only apply to large-scale digitalization of the sphere of sale and purchase, but also to those areas of law whose transfer to the Internet has never been expected before (public services, electronic voting right, etc.). Even more threatening is the problem of using darknet in criminal spheres.

The absence of any systemic legal regulation in this area or even a minimal set of basic legal terms makes domestic legislation defenseless against the rapidly developing darknet. The article proposes the authors' understanding of the main issues of the darknet as a subject of legal regulation, the balance of freedom and anonymity in the network and the protection of public and private interests. The framing of the concept of legal regulation in relation to darknet should serve as a starting point on this highly complex path.

Keywords: digital law; Internet law; Darknet; cryptocurrency; cybersecurity; anonymity; freedom
\end{abstract}


Интернет за последние два десятилетия стал неотъемлемым элементом человеческой жизни и новым (удобным и оперативным) инструментом коммуникации в обществе. Вне всякого сомнения, в цифровую эпоху значительная часть экономической, политической и культурной жизни протекает именно в интернете. Хозяйственная деятельность вышла на уровень электронной коммерции, интернет-банкинга, а ктивного использования систем хра нения и вычисления для минимизации издержек и роста прибыли (цифровая экономика). В сфере политики властные отношения трансформируются в новый формат взаимодействия государства и личности, в котором подчинение, господство, закрытость меняются на равноправие и прозрачность (электронное правительство). На конец, культура, в том числе коммуникация, от элитарности иприоритета прав автора переходит к массовости (социа льные сервисы и медиа) иоткрытости лицензии и пользования интеллектуальными продуктами.

Наряду с целым рядом преимуществ интернет вызвал к жизни не существовавшие ранее проблемы и задачи: обеспечение кибербезопа сности, за щита персональных данных, вопросы юрисдикции, идентифика ции пользователей и другие. Данные явления в той или иной мере находят организационные и юридические средства разрешения. Уровень осмысления проблем интернет-права в зарубежной и российской пра вовой науке можно признать хотя и начальным, но все -та ки доста точным (см., например, [Архипов 2018; Easterbrook 1996; Lessig 1999] и др.). В то же время из сферы правового регулирования ускользает Даркнет - сеть скрытого ианонимного интернета. При этом Даркнет выступает одним из уровней интернета. Первый уровень интернета включает в себя совокупность индексированных сайтов, пользователей которыхможно определить на основе IP адреса. Второй уровень - глубинный интернет (Dеер Internet)- представляет собой на бор неиндексированных стра ниц инте рнета, которые не могут быть найдены по поисковым системам, но пользователи которых могут быть идентифицированы. Отличительная черта Даркнета состоит в том, что его пользователи благодаря браузеруи системе шифрования сохраняют своюа нонимность и не могут быть идентифицирова ны.

Возникновение Даркнета связываютс первой интернет-сетью APRANET в 1970-хгг., когда интернет был субкультурой, не имел массового распространения и служил инструментом общения ученых. В 2002 г. термин Даркнет был использован впервые в книге сотрудников Microsoft «Даркнет и будущее распространения информации», в которой авторы выступили за идею свободы и конфиденциа льности в Интернете [Easterbrook 1996].

Рассужда я в философско-а нтропологическом ключе, следует отметить, что изначально появление Даркнета как анонимной сети было связано со стремлением людей к свободе от внешнего контроля и к творческой реализации. Не случайно сами технологии и Даркнет - предмет серьезной полемики между трансгума ниста ми и ана рхопримитивистами. Трансгума нисты говорят о безграничных возможностях человеческого интеллекта и рассматривают технологии ка к средство совершенствования человека и обще ства, вплоть до бессмертия (Золтан Истван, Андрес Стэндберг, теперь и Р. Курцвейл). Соответственно, сфера Даркнет для трансгуманистов - поле воплощения свободы духа и творческой энергии. Для анархопримитивистов любая технология есть на рушение естественной природы человека, поскольку технологии в итоге ведут к господству контроля и иерархии. Технологии стали превращать человека в зависимое существо, он перестал быть свободным (Джон Зерзан). Причем неолуддиты видят выход из технократического рабства в возврате к доцивилизационному обра зу жизни через «ревайлдинг» (буква льно одичание) [Lessig 1999: 256-281].

Главным преимуществом для тех, кто предпочитает Даркнет (по разным оценкам их число варьируется от 0,1\% до $1 \%$ от всех пользова телей инте рнета), выступа ет сохране ние анонимности пользователей. В техническом отношении та кая анонимность достигается за счет использования специальных браузеров TOR (луковых маршрутизаторов), которые не позволяют определить IP-адреса с помощью специальных способов шифрования и туннельной передачи данных. Информация в Даркнете передается в одноранговых сетях без возможности их контроля и перехвата [Biddle, England, Peinado, Willman 2003: 25].

Такая технология сохранения конфиденциальности пользователей сама по себе нейтральна, но может использоваться как во благо - для развития креативных форм общения, так и для общественно опасных деяний - торговля наркотическими средствами, размещение порнографического контента, продажа оружия, поиск убийц по на йму, на рушение прав на интеллектуальную собственность, виртуальная валюта и др. [Бартлетт 2017: 650]. При этом, по сложившемуся общему мнению, Даркнет ассоциируется только с кримина литетом, в то время как он успешно используется и для достижения безобидных целей. Полагаем, что преступными следует считать не технологии, а цели, для достижения которых они могут быть использова ны. Очевидно, что тяготение к кримина льной модели применения Даркнета заложено в а нонимности сети, что привлека ет различного рода злоумышленников, избега ющих идентифика ции и привлечения к юридической ответственности.

В за конодательстве Российской Федерации отсутствует определение Даркнета. Тем не менее, можно выделить ряд значимых для правового регулирования признаков:

1. Даркнет - это информационно-коммуникационная система для взаимодействия пользователей (также как и открытый интернет);

2. с точки зрения программного обеспечения Даркнетоснован на технологии TOR или его аналогах;

3. Даркнетобеспечиваетанонимность и конфиденциальность пользователей, поскольку их IP-адреса шифруются.

Подходы к госуда рственному контролю иправовому ре гулированию Даркнета можно разделить на 3 группы:

1. государственна я позиция, согласно которой Даркнет должен быть запрещен, поскольку он используется в криминальных целяхине позволяет идентифицировать правонарушителей;

2. позиция сторонников свободного интернета, выступающих против любого вмешательства и контроля со стороны госуда рства;

3. подход, учитыва ющий не возможность за прета Даркнета и нейтра льность оценки са мой а нонимной технологии социальной коммуникации. При этом в рамках последнего подхода отмечается не обходимость ка ктехнического, так и пра вового о твета на угрозы, которые несет Даркнет.

Полагаем, что третья позиция наиболее сбалансированна, поскольку в ней Даркнет предстает как инструмент, который приобретает общественную опасность в связи с преступными целями пользователей, а не сам по себе. Кроме того, текущий уровень развития не позволяет государствам блокировать использование Даркнета. Вместе с тем необходимо вырабатывать правовые и технические средства борьбыс его опасными проявлениями.

\section{Литература}

1. Архипов В.В. Интернет-право. Москва, 2018.

2. Easterbrook F. N. Cybers pace and the Law of the Horse / University of Chicago Legal Forum, 1996.

3. Lessig L. The Law of The Horse. What Cyberlaw Might Teach / Berkman Center for Internet \& Soci ety at Harvard University, 1999. 
4. Biddle P., England P., Peinado M., Willman B. The Darknet and the Future of Content Protection. In: Feigenbaum J. (Eds.). Digital Rights Management. DRM 2002. Lecture Notes in Computer Science, vol. 2696. Springer, Berlin, Heidelber, 2003. Doi: https://doi.org/10.1007/978-3-540-44993-5 10/

5. Бартлетт Д. Подпольный интернет: темная сторона мировой паутины. М., 2017.

6. Райтман М.А. Искусство ле га льного, а нонимного и безопа сного доступа к ресурсам Интернета. Екатеринбург, 2017.

7. Узденов Р.М. Новые границы киберпреступности / Всероссийский криминологический журнал. 2016. Т.10. № 4. С. 659 - 656.

\section{References}

1. Arhipov, V.V. (2018). The Internet law. [Internet-pravo]. Moscow (in Russian).

2. Bartl ett, J. (2017). The Dark Net. Inside the Digital Underworld. Moscow (in Russian).

3. Biddle, P., England, P., Peinado, M., Willman, B. (2003). The Darknet and the Future of Content Protection. In: Feigenbaum J. (Eds.). Digital Rights Management. DRM 2002. Lecture Notes in Computer Science, vol. 2696. Springer, Berlin, Heidelberg. Doi: https://doi.org/10.1007/9783-540-44993-5 10/

4. Easterbrook, F.N. (1996). Cyberspace and the Law of the Horse. University of Chicago Legal Forum, Vol. 1996, Article 7. Available at: https://chicagounbound.uchicago.edu/uclf/vol1996/iss1/7/

5. Lessig, L. (1999). The Law of The Horse. What Cyberlaw Might Teach. Berkman Center for Internet \& Soci ety at Harvard University.

6. Rajtman, M.A. (2017). The a rt of legal, anonymous and secure access to Internet re sources. [Iskusstvo legal'nogo, anonimnogo i bezopasnogo dos tupa k resursam Interneta]. Ekaterinburg (in Russian).

7. Uzdenov, R.M. (2016). New frontiers of cybercrime [Novye granicy kiberprestupnosti] /Vserossijskij kriminologicheskij zhurnal, 10(4), 659656 (in Russian).

\section{Citation:}

А.А. Васильев, Ж.И. Ибрагимов, О.В. Васильева. Даркнет как ускользающая сфера правового регулирования // Юрислингвистика. -2019. - №12.-С. 11-13. Vasiliev, A.A., Ibragimov, Zh.l., Vasileva, O.V. (2019). Darknet as an escaping sphere of legal regulation. Legal Linguistics, 12, 11-13.

(cc) Br This work is licensed under a Creative Commons Attribution 4.0. License 